\title{
The Effect Of Compensation And Employee Empowerment On Organization Citizenship Behavior (OCB) With Job Satisfaction As A Moderating Variable: Case Study On Production Employees PT. Real Glass Semarang
}

\author{
Patricia Dhiana Paramita ${ }^{1}$ dan Apriyanto Budhi Wibowo ${ }^{2}$ \\ ${ }^{1}$ Prodi Studi Manajemen Pandanaran Semarang, Indonesia \\ ${ }^{2}$ Teknik Sipil Universitas Pandanaran Semarang, Indonesia \\ Email corresponding author: wildblackrose27@gmail.com/apriyanto@unpand.ac.id
}

\begin{abstract}
ABSTRAK
PT. Real GlassSemarang adalah perusahaan yang bergerak di bidang pembuatan kaca hias mengalami permasalahan, dimana organization citizenship behavior (OCB) yang dimiliki oleh karyawan bagian produksi masih rendah, dimana hal tersebut diduga dilatarbelakangi oleh masih rendahnya kompensasi yang diterima oleh karyawan dan minimnya pemberdayaan yang diberikan oleh perusahaan terhadap karyawannya. Tujuan dari penelitian ini adalah untuk mengetahui pengaruh kompensasi dan pemberdayaan karyawan secara parsial dan simultan terhadap organization citizenship behavior (OCB) dan mengetahui apakah kepuasan kerja memperkuat pengaruh kompensasi dan pemberdayaan karyawan secara parsialterhadap organization citizenship behavior (OCB). Populasi dalam penelitian ini seluruh karyawan bagian produksi PT. Real GlassSemarang yang berjumlah80orang. Jumlah sampel yang diambil dalam penelitian ini ditentukan melaluimetode sensus, dengan mengambil sampel sebanyak 75orang atau keseluruhan dari total populasi karyawan yang bekerja di bagian produksi PT. Real GlassSemarang. Teknik analisis data yang digunakan adalah dengan MRA, goodness of fit berupa uji t dan koefisien determinasi. Hasil perhitungan menunjukkan bahwa kompensasi dan pemberdayaan karyawan secara parsial dan simultan berpengaruh positif dan signifikan terhadap organization citizenship behavior (OCB) dan disamping itu itu kepuasan kerja memperkuat pengaruh kompensasi dan pemberdayaan kayawan terhadap organization citizenship behavior (OCB).Sebaiknya manajemen PT. Real Glassmeningkatkan kompensasi serta pemberdayaan yang diberikan kepada karyawannya, sehingga dapat meningkatkan organization citizenship behavior (OCB).
\end{abstract}

Kata Kunci: kompensasi, pemberdayaan karyawan, organization citizenship behavior (OCB) dan kepuasan kerja

\section{ABSTRACT}

PT. Real Glass Semarang is a company engaged in the manufacture of decorative glass experiencing problems, where the organization citizenship behavior (OCB) owned by production employees is still low, which is thought to be motivated by the low compensation received by employees and the lack of empowerment provided by company towards its employees. The purpose of this study was to determine the effect of compensation and empowerment of employees partiallyand simultaneously on organization citizenship behavior $(O C B)$ and find out whether job satisfaction moderates the effect ofcompensation andemployee empowerment partially on organization citizenship behavior (OCB). The population in thisresearch were all employees of the production section of PT. Real GlassSemarang, amounting to 80 people. The number of samples taken in this research was determined 
through the census method, by taking a sample of 80people or thetotal population of employees working in the production section of PT. Real Glass Semarang. Thedata analysis technique used is the MRA, the goodness of fit is a test and the coefficient of determination. The calculation results show that compensation and employee empowerment partially and simultaneously have a positive and significant effect on the organization citizenship behavior $(O C B)$ andbesides that, job satisfaction strengthen the effect of compensation andempowerment of employees towards organizational citizenship behavior (OCB).It's betterfor the management of PT.Real Glass Semarang increasescompensation and empowerment given to its employees, so as to improve organization citizenship behavior $(O C B)$.

Keywords: Compensation, Employee Empowerment, Organization Citizenship Behavior $(O C B)$ and Job Satisfaction

\section{PENDAHULUAN}

Peran sumber daya manusia dalam suatu perusahaan sangatlah pentinguntuk menunjang keberlangsungan suatu perusahaan dalam menjalankan aktivitasnya.Oleh karena itu, agar aktivitas perusahaan akan dapat berjalan dengan baik sesuai dengan yang ditargetkan oleh perusahaandibutuhkan sumber daya manusia yang memiliki organization citizenship behavior (OCB) yang tinggi.Ditandai dengan karyawan akan mencurahkan perhatian, gagasan, dan tanggungjawabnya dalam upaya mencapai tujuan perusahaan (Mangkunegara, 2010 dalam Munandar, 2016).sehingga akan tercipta kinerja karyawan yang optimal selaras dengan yang diharapkan perusahaan. Perilaku yang menjadi tuntutan organisasi saat ini tidak hanya perilaku in-role, tetapi juga perilaku extra-role, yang sering juga disebut dengan organizational citizenship behavior (OCB).

Organizational Citizenship Behavior (OCB) merupakan perilaku yang lebih mengutamakan kepentingan orang lain, hal itu diekspresikan dalam tindakan-tindakan yang mengarah pada hal-hal yang bukan untuk tujuan memenuhi kepentingan pribadi, melainkan untuk mewujudkan terciptanya kesejahteraan orang lain (Sloat, 2001 dalam Ekawati, 2016).OCB yang muncul pada kinerja karyawan dipengaruhi dari berbagai faktor dalam organisasi, diantaranya karena adanya kepuasan kerja dari karyawan yang tinggi (Robbin dan Judge, 2008 dalam Ekawati, 2016). Kepuasan kerja dapat dimanifestasikan dengan adanya pemberian kompensasi sesuai dengan yang diharapkan oleh karyawan serta adanya pemberdayaan karyawan yang diberikan kepada para karyawannya (Luthans, 2003 dalam Ekawati, 2016).

Obyek dalam penelitian ini adalah karyawan bagian produksi yang bekerja di PT. Real GlassSemarang yaitu sebuah perusahaan yang bergerak di bidang usaha pembuatan kaca hias dan berlokasi di Kawasan Industri Gatot Subroto Semarang. Berdasarkan pengamatan awal yang dilakukan oleh peneliti, PT. Real GlassSemarang mengalami fenomena-fenomena permasalahan, yang mengindikasikan organization citizenship behavior (OCB) yang dimiliki oleh karyawan bagian produksi terhadap pekerjaan dan perusahaan tempatnya bekerja masih rendah.

Indikasinya tampak dari karyawan tidak memiliki motivasi untuk mencapai target produksi sebagaimana yang diharapkan oleh perusahaan, karyawan juga merasa enggan untuk berkorban waktu untuk bekerja ekstra keras demi kemajuan perusahaan termasuk adanya keengganan untuk melakukan lembur kerja dalam rangka menyelesaikan pekerjaan, karyawanjarang memiliki keinginan untuk membantu karyawan lainnya dalam menghadapi pekerjaan yang sulit, karena merasa bahwa pekerjaan tersebut bukan merupakan tugas maupun 
kewajibannya, karyawan tidak memiliki keinginan untuk berpartisipasi, bertanggung jawab dan terlibat dalam masalah-masalah organisasi serta tidak berusaha menjalankan pekerjaan lebih efektif dan efisien agar kinerja mereka lebih meningkat. Perilaku dari karyawan bagian produksi PT. Real GlassSemarang mengindikasikan bahwa organization citizenship behavior (OCB) yang dimiliki oleh mereka masih rendah.

Rendahnya organization citizenship behavior (OCB) yang dimiliki oleh karyawan PT. Real GlassSemarang diduga dilatarbelakangi oleh rendahnya kompensasi yang diberikan oleh perusahaan sertaminimnya program pemberdayaan yang dilakukan oleh perusahaan terhadap para karyawannya, sehingga kondisi tersebut berdampak pula pada rendahnya kepuasan kerja yang dimiliki oleh karyawannya.

Kompensasi adalah balas jasa yang diberikan oleh perusahaan kepada karyawannya yang dapat dinilai dengan uang dan mempunyai kecenderungan diberikan secara tetap (Nitisemito, 2012). Kompensasi dianggap sebagai kunci untuk mengelola sumber daya manusia secara efektif yang sesuai dengan kebutuhan bisnis dan kebutuhan karyawan (Sculler dan Jackson, 2013 dalam Prasetyo, 2016).

Selama ini kompensasi yang diberikan oleh PT. Real GlassSemarang terhadap karyawannya belum sesuaidengan yang diharapkan oleh para karyawan. Meskipun sudah ada Surat Kesepakatan Kerja antara karyawan dengan perusahaan, namun perusahaan masih sering mengingkarinya. Ditunjukkan dengan perusahaan masih sering terlambat dalam pembayaran gaji, belum adanya asuransi untuk kesehatan dan keselamatan kerja bagi karyawan bagian produksi, uang lembur yang diberikan kepada karyawan masih kurang memadai tidak sesuai dengan jam lembur dan pemberian kompensasi dirasakan masih kurang adil, dimana karyawan yang dekat dengan manajemen mendapatkan gaji lebih besar.

\section{KAJIAN PUSTAKA}

\section{Organizational Citizenship Behavior (OCB)}

Organizational Citizenship Behavior (OCB) yaitu perilaku pegawai melebihi apa yang telah distandarkan perusahaan (Krietner \& Kinicki, 2004 dalam Ekawati, 2016). Greenberg dan Baron (2006 dalam Ekawati, 2016), mengatakan bahwa OCBadalah tindakan yang dilakukan anggota organisasi yang melebihi dari ketentuan formal pekerjaannya. Karyawan dengan OCB tinggi, akan meningkatkan produktivitas dan kesuksesan dirinya di dalam suatu organisasi dan kesuksesan itu tidak dilakukan untuk dirinya sendiri saja tetapi juga untuk kepentingan organisasi itu sendiri.

\section{Kompensasi}

Kompensasi merupakan pengaturan keseluruhan pemberian balas jasa bagi employers maupun employee baik berupa finansial maupun non finansial (Martoyo, 2007 dalam Marginda, 2017). Kompensasi adalah balas jasa yang diberikan oleh perusahaan kepada karyawannya yang dapat dinilai dengan uang dan mempunyai kecenderungan diberikan secara tetap (Nitisemito, 2012). Karakteristik-karakteristik dari kompensasi menurut Luthan (2005 dalam Marginda, 2017) adalah sebagai berikut :1). arti penting, sebuah imbalan tidak akan dapat mempengaruhi apa yang dilakukan oleh orang-orang; 2).fleksibilitas, jika sistem imbalan di suatu perusahaan disesuaikan dengan karakteristik-karakteristik unik dari anggota individu; 3).frekuensi, semakin sering suatu imbalan diberikan; 4). Visibilitas, imbalan yang kelihatan (visible) dan memiliki keuntungan tambahan, karena mampu memuaskan kebutuhan-kebutuhan karyawan akan pengakuan dan penghargaan dan 5). Biaya,semakin rendah biayanya, semakin diinginkan imbalan tersebut dari sudut pandang organisasi. 


\section{Pemberdayaan Karyawan}

Pemberdayaan karyawan merupakan suatu usaha yang secara signifikan dapat menguatkan keyakinan wewenang untuk membuat keputusan dalam area kegiatan operasi tanpa harus memperoleh pengesahan orang lain (Luthan, 2005 dalam Marginda, 2017). Pemberdayaan karyawan (empowerment) adalah proses mendorong individu dalam organisasi untuk menggunakan inisiatif, kewenangan dan tanggung jawab dalam menyelesaikan pekerjaan (Sudarusman, 2004 dalam Marginda, 2017). Indikator-indikator dari pemberdayaan karyawan antara lain adalah karyawan merasa pekerjaan sudah sesuaidenganharapan, karyawan bertanggung jawab penuh terhadap pekerjaannya, karyawan memahami hak dan tanggung jawab sesuai dengan posisinya, karyawan selalu tepat waktu dalam melakukan pelaporan tugas dan karyawan memiliki ide kreatif untuk menyelesaikan pekerjaannya tanpa campur tangan atasan (Mangkuprawira dan Hubeis, 2007 dalam Ekawati, 2016).

\section{Kepuasan Kerja (Job Satisfaction)}

Kepuasan kerja adalah sikap umum pekerja yang menilai perbedaan antara jumlah yang seharusnya ia peroleh dengan yang didapat. Konsep kepuasan kerja menjadi tidak mudah karena berhubungan dengan perasaan dan persepsi manusia (Robbins, 2008 dalam Prasetyo, 2016). Kepuasan kerja merupakan generalisasi sikap-sikap terhadap pekerjaan yang didasarkan atas aspek-aspek pekerjaan seperti kompensasi gaji/upah, kondisi kerja, pengawasan, teman kerja, isi pekerjaan, jaminan kerja dan kesempatan promosi (Robbins, 2008, dalam Prasetyo, 2016). Menurut pendapat Gilmer (1966 dalam As'ad, 2015) tentang faktor - faktor yang mempengaruhi kepuasan kerja sebagai berikut : 1). kesempatan untuk maju, 2).keamanan kerja, 3). gaji, 4). manajemen kerja, 5). kondisi kerja, 6). pengawasan (supervisi), 7). faktor intrinsik dari pekerjaan,8). Komunikas, 9). aspek sosial dalam pekerjaan, 10).fasilitas

\section{Gambar 1}

\section{Kerangka Pemikiran Teoritis}

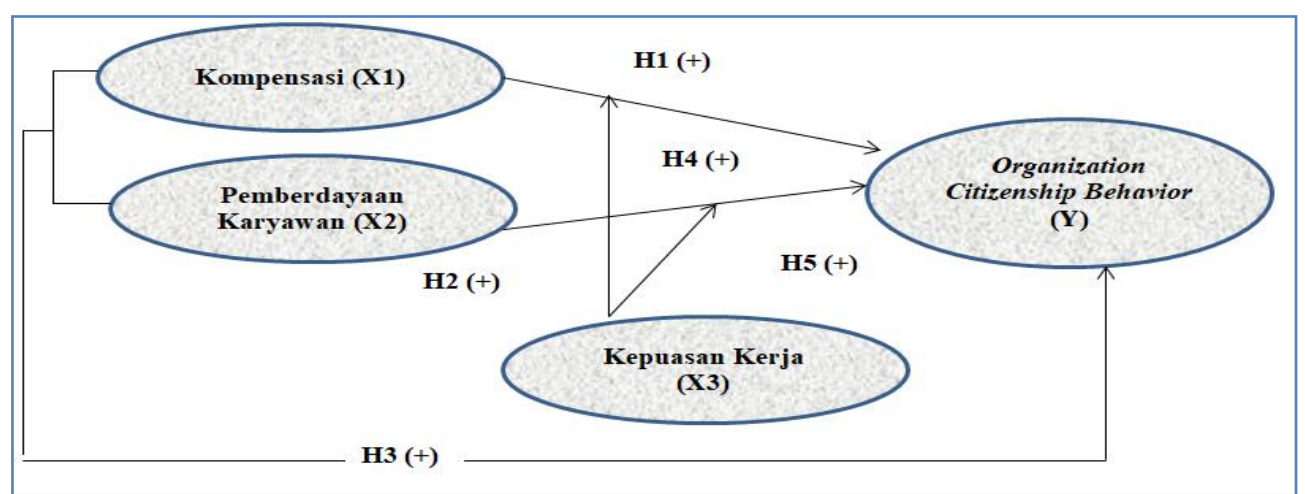

Sumber :Zuhri (2012), Nursanti dan Anissa (2014), Gusniati (2014), Fitrianasari (2016), Ekawati (2016), Tan dan Tarigan (2017), Suhardi dan Syaifullah (2017) dan Widarti (2018).

\section{METODE PENELITIAN}

\section{Varaibel Penelitian}

Variabel penelitian adalah suatu atribut, sifat atau nilai dari orang, obyek atau kegiatan yang memiliki variasi tertentu yang ditetapkan oleh peneliti untuk mempelajari dan kemudian ditarik kesimpulannya (Sugiyono, 2011).

Variabel yang digunakan dalam penelitian ini meliputi : 
1. Variabel independen, yaitu kompensasi $\left(\mathrm{X}_{1}\right)$ dan pemberdayaan karyawan $\left(\mathrm{X}_{2}\right)$

2. Variabel moderating, yaitu kepuasan kerja $\left(\mathrm{X}_{3}\right)$.

3. Variabel dependen, yaitu organizational citizenship behavior (OCB) (Y).

\section{Populasi dan Sampel}

Populasi adalah kumpulan semua individu atau obyek penelitian yang memiliki kualitas dan ciri-ciri yang telah ditetapkan(Arikunto, 2010). Adapun populasi dalam penelitian ini adalah seluruh karyawan yang bekerja di bagian produksi PT. Real Glass Semarang. Sampel merupakan sebagian dari populasi yang karakteristiknya hendak diselidiki dan dianggap bisa mewakili keseluruhan populasi dan jumlahnya lebih sedikit daripada jumlah populasinya (Djarwanto dan Pangestu, 2012). Jumlah sampel yang diambil dalam penelitian ini ditentukan melalui metode sensus, dimana semua populasi yang ada dipilih menjadi sampel (Hadi, 2013). Dengan mengambil sampel sebanyak 80orang atau keseluruhan dari total populasi karyawan bagian produksi PT. Real GlassSemarang.

\section{Jenis dan Sumber Data}

Jenis data yang digunakan adalah data subyek, yaitu jenis data penelitian yang berupa opini, sikap, pengalaman atau karakteristik dari seseorang atau sekelompok orang yang menjadi subyek penelitian (Ferdinand, 2016). Sumber data adalah tempat atau asal data yang diperoleh (Marzuki, 2015). Sumber data yang penulis pergunakan dalam penelitian ini adalah data primer.

\section{Metode Pengumpulan Data}

Metode pengumpulan data yang digunakan adalah angket atau kuesioner, dimana dalam penelitian ini jawaban yang diberikan oleh responden kemudian diberi skor dengan mengacu pada skala Likert.

\section{Teknik Analisis Data}

Teknik analisis data yang digunakan dalam penelitian ini antara lain dengan menggunakan analisis deskriptif yang dilakukan dengan teknik analisis indeks, uji instrumen berupa uji validitas dan reliabilitas, uji asumsi klasik berupa uji normalitas data, uji multikolonieritas, uji heteroskedastisitas, analisis regresi linier berganda dengan MRAdan ujiGoodness of Fit.

\section{HASIL DAN PEMBAHASAN}

\section{Uji Instrumen}

Uji instrumen yang digunakan dalam penelitian ini berupa uji validity dan reliability yang digunakan untuk mengetahui apakah data valid dan reliable. 


\section{Uji Validitas}

Tabel 1. Hasil Uji Validitas

\begin{tabular}{|c|c|c|c|}
\hline Wariabel Penelitian & r hitung & r tabel & Keterangan \\
\hline $\begin{array}{c}\text { Organization } \\
\text { Citizenship Behavior } \\
\text { (Y) }\end{array}$ & & & \\
\hline$Y .1$ & 0.659 & 0.22 & Valid \\
\hline Y.2 & 0.595 & 0.22 & Valid \\
\hline$Y .3$ & 0.612 & 0.22 & Valid \\
\hline Y.4 & 0.704 & 0.22 & Valid \\
\hline Y.5 & 0.669 & 0.22 & Valid \\
\hline \multicolumn{4}{|l|}{ Kompensasi (X1.1) } \\
\hline $\mathrm{X} 1.1$ & 0.826 & 0.22 & Valid \\
\hline $\mathrm{X} 1.2$ & 0.888 & 0.22 & Valid \\
\hline $\mathrm{X} 1.3$ & 0.829 & 0.22 & Valid \\
\hline $\mathrm{X} 1.4$ & 0.793 & 0.22 & Valid \\
\hline $\mathrm{X} 1.5$ & 0.834 & 0.22 & Valid \\
\hline \multicolumn{4}{|l|}{$\begin{array}{l}\text { Permberdayaan } \\
\text { Karyawan (X2) }\end{array}$} \\
\hline$\times 2.1$ & 0.829 & 0.22 & Valid \\
\hline$\times 2.2$ & 0.852 & 0.22 & Valid \\
\hline$\times 2.3$ & 0.883 & 0.22 & Valid \\
\hline$\times 2.4$ & 0.892 & 0.22 & Valid \\
\hline$\times 2.5$ & 0.874 & 0.22 & Valid \\
\hline \multicolumn{4}{|l|}{ Kepuasan Kerja (X3) } \\
\hline$\times 3.1$ & 0.773 & 0.22 & Valid \\
\hline$\times 3.2$ & 0.729 & 0.22 & Valid \\
\hline$\times 3.3$ & 0.835 & 0.22 & Valid \\
\hline$\times 3.4$ & 0.802 & 0.22 & Valid \\
\hline$\times 3.5$ & 0.795 & 0.22 & Valid \\
\hline
\end{tabular}

Sumber : Data primer yang diolah, 2021

Tabel 1 di atas merupakan hasil penghitungan uji validitas, yang digunakan untuk mengukur sah atau valid tidaknya suatu kuesioner (Arikunto, 2010) dan menunjukkan bahwa indikatorindikator dari semua variabel yang digunakan dalam penelitian ini adalah valid atau mampu mengukur data dari variabel yang diteliti secara tepat, karena nilai $r$ hitung masing-masing indikator variabel berada di atas nilai $\mathrm{r}$ tabel 0.22 (two tailed).

\section{Uji Reliabilitas}

Reliabilitas dilakukan untuk mengukur konsistensi konstruk atau variabel penelitian.Suatu variabel dikatakan reliable (handal) jika memiliki nilai Cronbach Alpha> 0,70.Adapun hasil dari pengujian reliabilitas adalah terdapat pada tabel 2.

Tabel 2. Hasil Uji Reliabilitas

\begin{tabular}{|l|c|c|c|}
\hline \multicolumn{1}{|c|}{ Variabel Penelitian } & $\begin{array}{c}\text { Cronbach } \\
\text { Alpha }\end{array}$ & Standar & Keterangan \\
\hline Organization Citizenship Behavior $(\mathrm{Y})$ & 0.888 & & Reliabel \\
Kompensasi $\left(\mathrm{X}_{1}\right)$ & 0.856 & & Reliabel \\
Pemberdayaan Karyawan $\left(\mathrm{X}_{2}\right)$ & 0.840 & 0.7 & Reliabel \\
Kepuasan Kerja $\left(\mathrm{X}_{3}\right)$ & 0.872 & & Reliabel \\
\hline
\end{tabular}

Sumber : Data primer yang diolah, 2021

Tabel 2 menunjukkan bahwa semua variabel yang digunakan dalam penelitian ini adalah reliabel atau handal, karena memiliki nilai koefisien Cronbach Alpha lebih besar dari nilai kritis yaitu 0,7 . 


\section{Uji Asumsi Klasik}

\section{Uji Normalitas Data}

Uji normalitas bertujuan menguji apakah dalam model regresi, variabel terikat dan variabel bebas keduanya mempunyai distribusi normal ataukah tidak.

Tabel 3. Uji Normalitas Data Regresi Model 1

\begin{tabular}{|c|c|c|c|c|}
\hline & & $\times 1$ & $\times 2$ & $Y$ \\
\hline $\begin{array}{l}\text { N } \\
\text { Normal } \\
\text { Parametersa,b } \\
\text { Most Extreme } \\
\text { Differences } \\
\text { Test Statistic } \\
\text { Asymp. Sig. (2 }\end{array}$ & $\begin{array}{l}\text { Mean } \\
\text { Std. Deviation } \\
\text { Absolute } \\
\text { Positive } \\
\text { Negative } \\
\text { iled) }\end{array}$ & $\begin{array}{r}80 \\
18.1250 \\
3.90836 \\
.186 \\
.067 \\
-186 \\
.186 \\
.530^{\circ} \\
\end{array}$ & $\begin{array}{r}80 \\
18.0250 \\
4.25746 \\
.223 \\
.081 \\
-.223 \\
.223 \\
.477^{\circ} \\
\end{array}$ & $\begin{array}{r}80 \\
18.3250 \\
3.50325 \\
-186 \\
.085 \\
-186 \\
-186 \\
.6312^{\circ}\end{array}$ \\
\hline
\end{tabular}

Sumber : Data primer yang diolah, 2021

Tabel 3 menunjukkan bahwa variabel penelitian, yaitu kompensasi $\left(\mathrm{X}_{1}\right)$, pemberdayaan karyawan $\left(\mathrm{X}_{2}\right)$ dan Organization Citizenship Behavior (OCB) (Y) memiliki nilai probabilitas masing-masing lebih besar daripada 0.05, maka dapat disimpulkan bahwa populasi berdistribusi normal.

\section{Uji Multikolonieritas}

Uji multikolonieritas dapat dilihat dari Variance Inflation Factor (VIF) dan nilai Tolerance(Gujarati, 2013).

Tabel 4. Hasil Uji MultikolonieritasRegresi Model 1

\begin{tabular}{|c|l|c|c|c|}
\hline No & \multicolumn{1}{|c|}{ Variabel Penelitian } & Tolerance & VIF & Keterangan \\
\hline 1. & Kompensasi $\left(\mathrm{X}_{1}\right)$ & 0.728 & 1.693 & Bebas multikol \\
2. & Pemberdayaan Karyawan $\left(\mathrm{X}_{2}\right)$ & 0.864 & 1.218 & Bebas multikol \\
\hline
\end{tabular}

Sumber : Data primer yang diolah, 2021

Berdasarkan tabel 4 dapat diketahui bahwa nilai VIF semua variabel bebas jauh di bawah 10 dan hasil perhitungan nilai tolerance menunjukkan semua variabel bebas memiliki nilai tolerance lebih besar dari 0.10, dengan demikian dapat disimpulkan tidak ada multikolonieritas antar variabel bebas dalam model regresi.

\section{Uji Heteroskedastisitas}

Pengujian heteroskedastisitasdalam penelitian ini menggunakan uji Glejser.Uji Glejser dilakukan dengan meregresikan variabel-variabel bebas terhadap nilai absolut residualnya (Gujarati, 2013).

Tabel 5. Uji Glejser Regression Model 1

\begin{tabular}{|c|c|c|c|c|c|}
\hline \multirow[b]{2}{*}{ Model } & \multicolumn{2}{|c|}{$\begin{array}{c}\text { Unstandardized } \\
\text { Coefficients }\end{array}$} & \multirow{2}{*}{$\begin{array}{c}\begin{array}{c}\text { Standardized } \\
\text { Coefficients }\end{array} \\
\text { Beta }\end{array}$} & \multirow[b]{2}{*}{$\mathrm{t}$} & \multirow[b]{2}{*}{ Sig. } \\
\hline & B & $\begin{array}{l}\text { Std. } \\
\text { Error }\end{array}$ & & & \\
\hline $1 \quad$ (Constant) & 4.738 & .923 & & 5.133 & .000 \\
\hline Kompensasi (X1) & .024 & .048 & .050 & .399 & .795 \\
\hline Pemberdayaan Karyawan (X2) & .021 & .037 & .044 & .356 & .781 \\
\hline
\end{tabular}

Sumber : Data primer yang diolah, 2021 
Tabel 5 menunjukkan bahwanilai signifikansisemua variabel yang digunakan penelitianlebih besar dari 0.05 , maka dapat disimpulkan data tidak terjadi masalah heteroskedastisitas.

\section{Analisis Regresi}

\section{Analisis Regresi Linier Bertahap}

Analisis regresi linear bertahapdigunakan untukmenguji adanyapengaruh variabel independen terhadap variabel dependen (Ghozali, 2016).

Tabel 6.Hasil Uji Regresi Model 1

\begin{tabular}{|ll|r|r|r|}
\hline \multicolumn{1}{|l|}{ Model } & \multicolumn{3}{|c|}{ Unstandardized Coefficients } & $\begin{array}{c}\text { Standardized } \\
\text { Coefficients }\end{array}$ \\
\cline { 3 - 5 } & & \multicolumn{1}{|c|}{ B } & \multicolumn{1}{c|}{ Std. Error } & \multicolumn{1}{c|}{ Beta } \\
\hline \multirow{2}{*}{1} & (Constant) & 3,578 & 1,726 & \\
& Kompensasi $\left(X_{1}\right)$ &, 355 &, 114 &, 381 \\
& Pemberd. Kary $\left(X_{2}\right)$ &, 217 &, 073 &, 245 \\
\hline
\end{tabular}

Sumber : Data primer yang diolah, 2021

Tabel 6 menunjukkan perhitungan hasil regresi model 1, dimana dapat dibuat persamaan regresi yang mencerminkan hubungan antara variabel-variabel yang digunakan dalam penelitian ini, yaitu :

$$
\mathrm{Y}=3.578+0.355 \mathrm{X}_{1}+0.217 \mathrm{X}_{2}+\mathrm{e}
$$

\section{Analisis Regresi Berganda dengan MRA}

Moderated Regression Analysis (MRA) atau uji interaktif merupakan aplikasi khusus regresi linier berganda, dimana dalam persamaan regresinya mengandung unsur interaksi(perkalian dua atau lebih variabel independen).

Tabel 7. Hasil Uji Regression Model 2 dengan MRA

\begin{tabular}{|c|c|c|c|c|}
\hline \multirow{2}{*}{\multicolumn{2}{|c|}{ Model }} & \multicolumn{2}{|c|}{$\begin{array}{l}\text { Unstandardized } \\
\text { Coefficients }\end{array}$} & \multirow{2}{*}{$\begin{array}{l}\text { Standardized } \\
\text { Coefficients } \\
\text { Beta }\end{array}$} \\
\hline & & $\mathrm{B}$ & Std. Error & \\
\hline \multirow[t]{5}{*}{1} & (Constant) & 11.018 & 2.590 & \\
\hline & Kompensasi. (X1) & .368 & 238 & .399 \\
\hline & Pemberd. Karyawan (X2) & .391 & .248 & .447 \\
\hline & Moderate 1 (X1X3) & .116 & .112 & .858 \\
\hline & Moderate $2(\times 2 \times 3)$ & .124 & .062 & .745 \\
\hline
\end{tabular}

Sumber : Data primer yang diolah, 2021

Tabel 7 menunjukkan perhitungan hasil regresimodel 2 denganMRA, dimana dapat dibuat persamaan regresi yang mencerminkan hubungan antara variabel-variabel yang digunakan dalam penelitian ini, yaitu :

$Y=11.018+0.368 X_{1}+0.391 X_{2}+0.116 X_{1} X_{3}+0.124 X_{2} X_{3}+e$

\section{Pengujian Goodness of Fit}

Uji Signifikansi Individual (Uji t)

Tabel 8. Ujit Regression Model 1

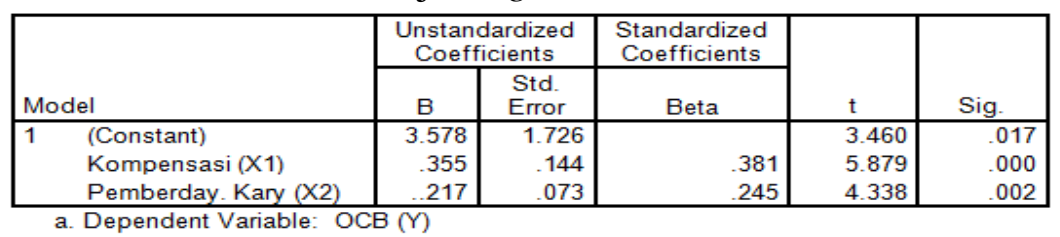


Sumber : Data primer yang diolah, 2021

\section{Hipotesis Pertama $\left(\mathrm{H}_{1}\right)$}

Kompensasi memiliki nilai $\mathrm{t}$ hitung sebesar 5.879> t tabel 1.66462 dan tingkat signifikansi $\mathrm{t}$ hitung $0.000<\alpha=0.05$ (one taile) dan bertanda positif, maka hipotesis pertama $\left(\mathrm{H}_{1}\right)$ yang menyatakan bahwa kompensasi berpengaruh positif dan signifikan terhadap Organizational Citizenship Behavior (OCB) pada karyawan bagian produksi PT. Real GlassSemarang dapat diterima.

\section{Hipotesis Kedua (H2)}

Pemberdayaan karyawan memiliki nilai t hitung sebesar 4.338>t tabel 1.66462 dan tingkat signifikansi t hitung $0.002<\alpha=0.05$ (one taile) dan bertanda positif, maka hipotesis kedua $\left(\mathrm{H}_{2}\right)$ yang menyatakan bahwa pemberdayaan karyawan berpengaruh positif dan signifikan terhadap Organizational Citizenship Behavior (OCB) pada karyawan bagian produksi PT. Real Glass Semarang dapat diterima.

\section{Uji Signifikansi Parameter Simultan (Uji F) Pengujian Hipotesis Ketiga (H3)}

Tabel 9. Uji F Regression Model 1

\begin{tabular}{|c|c|c|c|c|c|c|}
\hline \multicolumn{7}{|c|}{ ANOVA $^{a}$} \\
\hline & & Sum of Squares & $\mathrm{df}$ & Mean Square & $\mathrm{F}$ & Sig. \\
\hline \multirow[t]{3}{*}{1} & Regression & 535.238 & 3 & 171.513 & 31.939 & $.000^{\mathrm{b}}$ \\
\hline & Residual & 434.512 & 76 & 5.294 & & \\
\hline & Total & 949.450 & 79 & & & \\
\hline
\end{tabular}

Sumber : Data primer yang diolah, 2021

Nilai F hitung $31.939>\mathrm{F}$ tabel 2.72 dan tingkat signifikansi $0.000<\alpha=0.05$, makahipotesis ketiga $\left(\mathrm{H}_{3}\right)$ yang menyatakan bahwa kompensasi dan pemberdayaan karyawan secara simultan berpengaruh posistif dan signifikan terhadap Organizational Citizenship Behavior (OCB) pada karyawan bagian produksi PT. Real GlassSemarang dapat diterima.

Pengujian Hipotesis Keempat $\left(\mathrm{H}_{4}\right)$

Tabel 10. UjitRegression Model 2 dengan MRA

\begin{tabular}{|c|c|c|c|c|c|c|}
\hline \multirow{2}{*}{\multicolumn{2}{|c|}{ Model }} & \multicolumn{2}{|c|}{$\begin{array}{c}\text { Unstandardized } \\
\text { Coefficients }\end{array}$} & \multirow{2}{*}{$\begin{array}{c}\begin{array}{c}\text { Standardized } \\
\text { Coefficients }\end{array} \\
\text { Beta }\end{array}$} & \multirow[b]{2}{*}{$\mathrm{t}$} & \multirow[b]{2}{*}{ Sig. } \\
\hline & & & $\begin{array}{l}\text { Std. } \\
\text { Error }\end{array}$ & & & \\
\hline & (Constant) & 11.018 & 2.590 & & 8.219 & .000 \\
\hline & Kompensasi (X1) & 368 & .238 & 399 & 3.493 & .002 \\
\hline & Pemberd. Kary (X2) & 391 & 248 & .447 & 2.914 & .010 \\
\hline & Moderate 1 (X1X3) & 116 & .112 & .858 & 2.493 & .020 \\
\hline & Moderate $2(\times 2 \times 3)$ & 124 & .062 & 745 & 1.783 & .005 \\
\hline
\end{tabular}

Sumber : Data primer yang diolah, 2021

Variabel moderate 1 yang merupakan interaksi antara kompensasi dan kepuasan kerja hasilnya signifikan, sehingga hipotesis keempat $\left(\mathrm{H}_{4}\right)$ yang menyatakan bahwa kepuasan kerja memperkuat pengaruh kompensasi terhadap Organizational Citizenship Behavior (OCB) pada karyawan bagian produksi PT. Real GlassSemarang dapat diterima. 


\section{Pengujian Hipotesis Kelima $\left(\mathbf{H}_{5}\right)$}

Variabel moderate 2 yang merupakan interaksi antara pemberdayaan karyawan dan kepuasan kerja ternyata signifikan, sehingga hipotesis kelima $\left(\mathrm{H}_{5}\right)$ yang menyatakan bahwa kepuasan kerja memperkuat pengaruh pemberdayaan karyawan terhadap Organizational Citizenship Behavior (OCB) pada karyawan bagian produksi PT. Real GlassSemarang dapat diterima.

\section{Koefisien Determinasi (R Square)}

Tabel 11 Hasil Uji Koefisien Determinasi Regression Model 1

\begin{tabular}{|c|c|c|c|c|}
\hline \multicolumn{5}{|c|}{ Model Summary } \\
\hline Model & $\mathrm{R}$ & R Square & $\begin{array}{c}\text { Adjusted R } \\
\text { Square }\end{array}$ & $\begin{array}{l}\text { Std. Error of the } \\
\text { Estimate }\end{array}$ \\
\hline 1 & $.850^{\mathrm{a}}$ & .762 & 723 & 1.79456 \\
\hline
\end{tabular}

Sumber : Data primer yang diolah, 2021

Tabel 12 Hasil Uji Koefisien Determinasi Regression Model2 dengan MRA

\begin{tabular}{|l|r|r|r|c|}
\hline Model & $\mathrm{R}$ & $\mathrm{R}$ Square & $\begin{array}{c}\text { Adjusted R } \\
\text { Square }\end{array}$ & $\begin{array}{c}\text { Std. Error of the } \\
\text { Estimate }\end{array}$ \\
\hline 1 & $.957^{\mathrm{a}}$ & .902 & .898 & 1.79456 \\
\hline
\end{tabular}
a. Predictors: (Constant), Moderate 2(X2X3), Pemberd. Kary (X2),
Kompensasi. (X1), Moderate 1 (X1X4)

Sumber : Data primer yang diolah, 2021

Adjusted $R^{2}$ pada Regression Model 1 sebesar 0.723 yang artinya variasi variabel Organizational Citizenship Behavior (OCB) pada karyawan bagian produksi PT. Real GlassSemarang dapat dijelaskan oleh variabelkompensasi dan pemberdayaan karyawan sebesar 0.723 atau 72.3 persen, sedangkan sisanya sebesar27.7 persen dipengaruhi oleh variabel-variabel lain di luar model. Nilai Adjusted $R$ Square $\left(\mathrm{R}^{2}\right)$ pada Regression Model 2 dengan MRA sebesar 0.898, artinya 89.8 persen variasi variabel Organizational Citizenship Behavior (OCB) pada karyawan bagian produksi PT. Real GlassSemarang dapat dijelaskan oleh variabelkompensasi, pemberdayaan karyawan, moderate 1 dan 2 sebesar 0.898 atau 89.8 persen, sedangkan sisanya sebesar 10.2 persen dipengaruhi oleh variabel-variabel lain di luar model.

\section{KESIMPULAN DAN SARAN}

1. Kompensasi berpengaruh positif dan signifikan terhadap Organizational Citizenship Behavior (OCB) pada karyawan bagian produksi PT. Real GlassSemarang.

2. Pemberdayaan karyawan berpengaruh positif dan signifikan terhadap Organizational Citizenship Behavior (OCB) pada karyawan bagian produksi PT.

Real GlassSemarang.

3. Kompensasi dan pemberdayaan karyawan secara simultan berpengaruh positif dan signifikanterhadap Organizational Citizenship Behavior (OCB) pada karyawan bagian produksi PT. Real GlassSemarang.

4. Kepuasan kerja memperkuat pengaruh kompensasi terhadap Organizational Citizenship Behavior (OCB) padakaryawan bagian produksi PT. Real Glass

Semarang. 
5. Kepuasan kerja memperkuat pengaruh pemberdayaan karyawan terhadap Organizational Citizenship Behavior (OCB) pada karyawan bagian produksi PT. Real GlassSemarang.

\section{Keterbatasan Penelitian}

1. Adanya keterbatasan pada variabel independen yang digunakan, yaitu variabel kompensasi dan pemberdayaan karyawan sebagai variabel independen.

2. Obyek dalam penelitian adalah organisasi yang sifatnya dinamis, sehingga hasil penelitian ini belum bisa digeneralisasikan bagi semua permasalahan, karenahanya menggambarkan kondisi Organizational Citizenship Behavior dan kepuasan kerja yang dimiliki oleh karyawan bagian produksi PT. Real GlassSemarang yang belum tentu sama bila diterapkan di perusahaan lainnya.

\section{Agenda Penelitian Mendatang}

Untuk penelitian selanjutnya dapat menambahkan faktor-faktor lain yang berpengaruh terhadap Organizational Citizenship Behavior, seperti Person komitmen organisasi, Organization Fit (PO-Fit), kepuasan kerja dan budaya organisasi. Disamping itu dapat digunakan variabelpenghargaan (rewards), human relation, rekan kerja, pengembangan karir dan tunjanganuntuk mengukur kepuasan kerja.

\section{Saran}

Sebaiknya manajemen PT. Real GlassSemarang meningkatkan kompensasi serta pemberdayaan yang diberikan kepada karyawannya, sehingga dapat meningkatkan kepuasan kerja karyawan yang akan berdampak positif bagi organization citizenship behavior (OCB).

\section{DAFTAR PUSTAKA}

Alex S. Nitisemito, 2012. Manjemen Personalia, Jakarta : Ghalia Indonesia

Arikunto, Suharsimi. 2010. Prosedur Penelitian: Suatu Pendekatan Praktek, Jakarta: Rineka Cipta

Damodar, Gujarati, 2014.Ekonometrika Dasar, Jakarta: Erlangga

Dian, Kurnia Ekawati, 2016. Determinan Organization Citizenship Behavior (OCB) Dengan Afective Commitment Sebagai Moderating Variabel (Studi Pada PegawaiDinas Pasar Kota Semarang), Jurnal Magister Manajemen Universitas Semarang.

Ghozali, Imam. 2016. Aplikasi Analisis Multivariate Dengan Program SPSS, Semarang: Badan PenerbitUniversitas Diponegoro.

Ekawati, Kurnia Dian, 2016. Determinan Organizational Citizenship Behavior (OCB) Dengan Affective Commitment Sebagai Moderating Variabel (Studi Kasus Pada Pegawai Dinas Pasar Kota Semarang), Jurnal Magister Manajemen Universitas Semarang.

Ferdinand, Augusty, 2016. Manajemen Pemasaran : Sebuah Pendekatan Strategic, Semarang: BP. Undip

Fitrianasari, Dini, dkk, Fakultas Ilmu Administrasi Universitas Brawaijaya Malang

Gusniati, 2014. Pengaruh Pemberdayaan Psikologis dan Kepuasan Kerja Terhadap OCB Pada PT. Karya Bajatama Raya Dengan Dukungan atasan Sebagai Variabel Moderator, Jurnal Universitas Bina Nusantara.

Munandar, 2016. Pengaruh Karakteristik Pekerjaan, Pemberdayaan Pegawai dan Kualitas Kehidupan Kerja Terhadap Komitmen Organisasi Dengan Person Organization Fit Sebagai Variabel Intervening (Studi Pada Pegawai Dinas Pasar Kota Semarang), Jurnal Magister Manajemen Universitas Semarang. 
Marginda, Garnes Petriamery, Pengaruh Kompensasi, Pemberdayaan Karyawan dan Human Relations Terhadap Komitmen Afektif yang Berdampak Pada Prestasi Kerja Karyawan Bagian Produksi PT. Lintang Kejora Semarang, Jurnal Magister Manajemen Universitas Semarang.

Nitisemito, Alex, 2012. Manajemen Personalia, Jakarta : Gramedia

Nursanti, Tinjung Desy dan Aida Dwi Anissa, 2014. Pengaruh Dukungan Supervisor dan Pemberdayaan Terhadap Organizational Citizenship Behavior, Binus Business Review, Volume 5 No 1.

Penulis, T., Enas, U., Zunaidi, A., Pribadi, Y., Syairozi, I., Andri, B., Uliansyah, A., Sunyoto, E., Sijabat, R., Sarasi, V., Sugiri, D., Hastanti, A., Rahayu, D. C., Pangestuti, A. A., \& Pratama, S. (2021). KEUANGAN NEGARA. www.penerbitwidina.com

Sugiharto, Andi Hutapea, dkk, 2016. Pengaruh Pengembangan Karir dan Kualitas Kehidupan Kerja Terhadap Kepuasan Keja Dimediasi Person Organization Fit (Studi Pada Karyawan PT. HD Trans Semarang), Journal of Management, Vol. 02 No.02, Maret 2016.

Susanti, I., Syairozi, M. I., \& Lukman, H. Y. W. (2021). Analisis Sistem Manajemen Dalam Pengelolaan Bumdes Di Desa Bluluk. Jurnal Sains Sosio Humaniora, 5(2), 701-710.

Sugiyono, 2011. Metode Penelitian Bisnis, CV. Alfabeta, Bandung

Syairozi, M. I. (2017). Aplikasi Akad Musyarakah pada Pembiayaan Unit Usaha Syariah PT Bank Rakyat Indonesia (PERSERO), Tbk. PROCEEDINft, 111.

Tan, Raymond dan Zeplin Jiwa Husada Tarigan, 2017. Pengaruh Kompensasi dan Kepuasan Kerja Terhadap OCB Melalui Motivasi Kerja Sebagai Variabel Intervening Pada $3 \mathrm{H}$ Motosport, Jurnal AGORA, Volume 5 Nomor 1.

Widarti, Novia Anjar, 2018. Pengaruh Kompensasi, Komitmen Organisasional dan Kepuasan Kerja Terhadap Organizational Citizenship Behavior (OCB) (Studi Pada Karyawan PT. BRI Persero Tbk. Kantor Cabang Tanjung Karang), Tesis, Program Pasca Sarjana Universitas Lampung

Zuhri, Moh. Syaifudin, 2012. Pengaruh Kompensasi Langsung dan Kompensasi Tidak Langsung Terhadap OCB Melaui Kepuasan Kerja (Studi Pada Karyawan KUD Batu Kota Wisata Batu, Skripsi, Universitas Islam Negeri Maulana Malik Ibrahim Malang. 